\title{
Native insectary plants support populations of predatory arthropods for Australian vineyards
}

\author{
M. Retallack ${ }^{1,2, a}$, L. Thomson ${ }^{3}$, and M. Keller ${ }^{2}$ \\ ${ }^{1}$ Retallack Viticulture Pty Ltd, 125 Sheoak Road, Crafers West, South Australia 5152, Australia \\ ${ }^{2}$ School of Agriculture, Food and Wine, The University of Adelaide, Glen Osmond, South Australia 5064, Australia \\ ${ }^{3}$ School of BioSciences, The University of Melbourne, Parkville, Victoria 3010, Australia
}

\begin{abstract}
We provide a summary of two recent studies that investigated the role that three native insectary plants can play in promoting predatory arthropods, and thereby to enhance biological control of vineyard pests in Australia. Native plants are preferred as supplementary flora, as they are locally-adapted to Australia's climatic conditions. Stands of mature Bursaria spinosa, Leptospermum continentale and Rytidosperma ssp. located adjacent to, or in vineyards, in South Australia were sampled for arthropods in 2013/14. Grapevines were also sampled to explore relationships between each plant and associated arthropods using common diversity indices. Twenty seven thousand and ninety-one individual invertebrate specimens were collected, comprising 20 orders and 287 morphospecies. These were categorised into functional groups of predators, herbivores and other. Predatory arthropods dominated the diversity of morphospecies present on each plant. The richness of predator morphospecies across all plant types was nearly double the number found in association with grapevines. It may be possible to increase the functional diversity of predatory arthropods by more than $3 \mathrm{x}$ when either B. spinosa or L. continentale is present versus grapevines only, and increase the net number of predator morphospecies by around $27 \%$ when Rytidosperma ssp. are planted in combination with grapevines. The selected plants provide a suitable habitat to support diverse and functional populations of predatory arthropods. The opportunity to plant selected native insectary species could help wine grape growers save time and resources by producing fruit with lower pest incidence, while enhancing biodiversity associated with vineyards.
\end{abstract}

\section{Introduction}

Economic damage is caused in Australian vineyards each season by pest species [1]. Light brown apple moth (LBAM), Epiphyas postvittana (Walker) (Lepidoptera: Tortricidae), is the principal insect pest that causes economic damage in Australian vineyards. Epiphyas postvittana causes damage to flower clusters resulting in yield losses and damage to berry skins. Damaged skins provide infection sites for Botrytis cinerea and other bunch moulds, which may result in a reduction in fruit quality and yield losses [2]. Other common vineyard pests include the Australian grapevine moth, weevils, mealybugs, scales and mites [3].

Biological control is a key component of arthropodmediated ecosystem services (AMES), which are used to manage pests in production systems [4]. Predatory arthropods found in association with insectary plants have the capacity to provide biological pest control in vineyards [5-8]. Conservation biological control (CBC) involves the implementation of practices that protect and enhance the reproduction, survival, and efficacy of natural enemies of pests [9-13]. CBC is defined as the conservation and augmentation of predatory arthropods that are already in place or are readily available [9]. Stands of native vegetation adjacent to perennial production areas including vineyards, have been associated with increased

a e-mail: mary@viti.com.au biodiversity benefits $[14,15]$. The majority of predators that attack crop pests are native [16]. Their presence in the vineyard can be boosted by incorporating native insectary plants [17].

Insectary plants provide food, shelter and alternative prey or hosts $[18,19]$, which nourish and support the presence of predatory arthropods in association with a focal crop plant, such as grapevines. Insectary plants need to be attractive to predators and parasitic species ('predators') but not to pests, and be easy to establish and maintain, without actively competing with grapevines.

A small suite of exotic insectary plants, including buckwheat, alyssum, and phacelia, has come to dominate the habitat management literature and they are frequently used in areas outside of their native ranges [12,20,21]. In Australia, they are not always easy to establish and maintain. Hence, locally-adapted native plants are preferred as supplementary flora, as they are naturally adapted to Australia's various climatic conditions [22,23].

Increased biodiversity is often promoted as an important indicator of vineyard health but it can be difficult to measure [24,25]. Thomson et al. [3] suggest that a surrogate indicator such as the diversity of predatory arthropods, which have a direct impact on pest abundance, can be used as one way to assess the benefits of enhancing biodiversity.

There is little information available describing the key relationships between predators in the vineyard and native

(c) The Authors, published by EDP Sciences. This is an Open Access article distributed under the terms of the Creative Commons Attribution License 4.0 (http://creativecommons.org/licenses/by/4.0/). 
insectary resources in Australia. We aim to determine if selected candidate insectary plants have the capacity to support populations of predatory arthropods throughout the year, and if they may also provide habitat for economically damaging vineyards pests.

We collected arthropods on the canopies of Christmas bush, Bursaria spinosa (Cav.), prickly tea-tree, Leptospermum continentale (Forst. and G.Forst) and wallaby grasses, Rytidosperma ssp. (DC) adjacent to or in the midrows of Adelaide Hills, Barossa Valley and Eden Valley vineyards during 2013/14. Vitis vinifera (L.) (Vitales: Vitaceae) was also sampled for comparison with the locally-adapted native insectary plants.

This paper brings together work carried out by Retallack et al. [26] and further analyses of common biodiversity indices [27]. It aims to broaden our understanding of biological and functional diversity offered by these native insectary plants, as model species that can be incorporated in and around Australian vineyards to boost the presence of predatory arthropods.

\section{Materials and methods}

Surveys were conducted at six locations in South Australia, four were in the Adelaide Hills and one each in the Barossa Valley and Eden Valley [26]. Three sampling methods were employed. A modified sweep net was used to sample the native woody vegetation. Each sample from $B$. spinosa or L. continentale was collected by firmly shaking the foliage five times, inside an insect sweep net $(370 \mathrm{~mm}$ in diameter), modified to hold a funnel and a $250 \mathrm{~mL}$ collection container. This process was repeated five times to form a composite sample. Samples from grapevines were collected by firmly striking the cordons five times with a rubber mallet, over a beat net $(700 \times 700 \mathrm{~mm})$ that held a $250 \mathrm{~mL}$ collection container. This process was repeated five times for each composite sample, alternating between each side of a pair of vine rows. A total of ten composite samples were collected per sampling date at each site with the modified sweep net and beat net capture techniques. Arthropods were killed in the field using ethyl acetate. Plants of Rytidosperma ssp. were sampled using ten pitfall traps at each site, exposed for two weeks prior to collection. Samples were collected fortnightly from September to December, and monthly in March, May and August during 2013/14. Arthropods were extracted, sorted to order, family and/or morphospecies. Refer to [26] for a full description of the sampling methods.

\subsection{Data analysis}

Due to zero inflated data the ten sweep net samples, ten beat net samples, and ten pitfall samples from the respective vegetation types were each pooled to give a single sample for each of the nine sample sites, and each sampling date. Replicated incidence data were assessed to determine observed morphospecies richness for each plant and to calculate associated diversity indices. To determine the influence of each plant species on the total sampled arthropod community, basic and compound diversity indices were calculated for each. Species accumulation curves were used to demonstrate the adequacy of sampling effort.
To determine the influence of each plant species on the total sampled arthropod community, basic and compound diversity indices were calculated for each. A basic index comprised richness (S), or the number of morphospecies present, is the simplest metric used to represent diversity [28]. The compound index H' ("Shannon") was calculated using the R package "Vegan" [29]. While a number of different indices are available and show different aspects of diversity, H' was chosen as it clearly demonstrates the diversity of arthropods associated with each plant when morphospecies are considered together in total and in functional groups. It is regarded by Jost [30] as the most useful of all diversity indices. H' $(\mathrm{x})$ was converted to a true diversity $p_{i}$ for each plant following Jost [30]. The value of $p_{i}$ takes into account the 'effective number of species' as defined by Macarthur [31], who introduced a method for transforming diversity indices to a species richness scale. True diversity is also known as the 'numbers equivalent' of diversity [32,33]. Randomised morphospecies accumulation curves were constructed for each plant and their associated arthropod communities, using the R package "Vegan" [29]. These curves show the number of species that you would expect to see if you collected a designated number of samples from each site.

Data were cast in contingency tables and the Jaccard similarity index was calculated [34] to determine the similarity of arthropods found between each combination of plants. Results of diversity indices for predators only are presented here.

\section{Results}

\subsection{Arthropods}

Twenty seven thousand and ninety-one arthropods were categorised into different functional groups, as either predators (including parasitoids), herbivores, or other (alternative prey, scavenger, seed or pollen feeders, detritivores), following the feeding habits outlined in Naumann's [35] arthropod identification keys. The complete dataset is presented in Retallack et al. [26].

\subsection{Predatory arthropods}

\subsubsection{Predatory morphospecies accumulation curves}

Randomised morphospecies accumulation curves are clearly approaching an upper asymptote in every case, which reflect the estimated total numbers of predatory arthropod morphospecies that are associated with each plant. Species accumulation curves for predatory arthropod morphospecies showed two groups comprising the arthropods associated with $B$. spinosa and $L$. continentale, and then V. vinifera and Rytidosperma ssp. (Fig. 1).

\subsubsection{Arthropod morphospecies richness}

Predatory arthropods dominated the morphospecies present on each plant. Captures on the woody, evergreen shrubs B. spinosa (67 morphospecies) and L. continentale (63) were associated with the highest richness of predator morphospecies, followed by $V$. vinifera (56) and native perennial grasses, Rytidosperma ssp. (38). The richness 
Table 1. Estimated similarity of morphospecies pairs (Jaccard's similarity coefficient) for predator morphospecies.

\begin{tabular}{|c|c|c|c|c|}
\hline \multirow[t]{2}{*}{ Focal plant species } & \multicolumn{4}{|c|}{ Comparative plant species } \\
\hline & $n=$ morphospecies & Bursaria spinosa & Leptospermum continentale & Vitis vinifera \\
\hline \multicolumn{5}{|l|}{ Predator } \\
\hline Bursaria spinosa & 67 & & & \\
\hline Leptospermum continentale & 63 & 0.67 & & \\
\hline Vitis vinifera & 56 & 0.52 & 0.59 & \\
\hline Rytidosperma ssp. & 38 & 0.25 & 0.23 & 0.32 \\
\hline
\end{tabular}

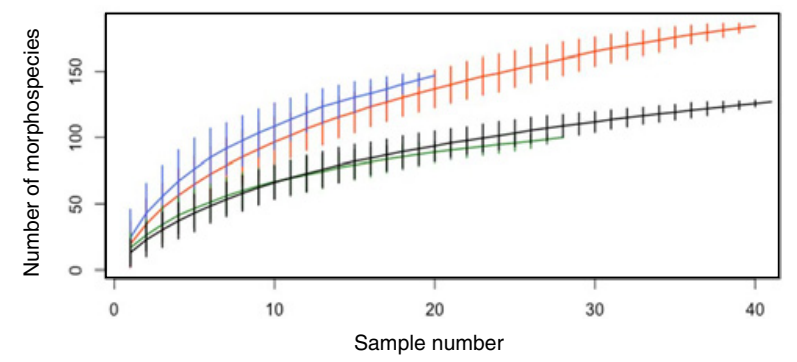

Figure 1. Randomised species accumulation curves generated using the total number of arthropod morphospecies found in association with Bursaria spinosa (red line), Leptospermum continentale (blue line), Vitis vinifera (black line), and Rytidosperma ssp. (green line).

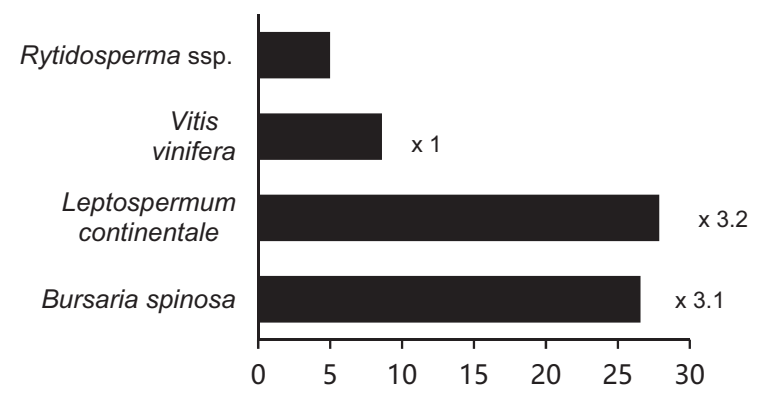

Figure 2. Predatory arthropod morphospecies diversity (Shannon's index) for each plant. The $\mathrm{x}$ increase in functional diversity by Bursaria spinosa, and Leptospermum continentale when compared to Vitis vinifera.

of predator morphospecies across all plant types $(S=98)$ was nearly double the number found in association with grapevines $(S=56)$.

\subsubsection{Estimated true diversity $\left(p_{i}\right)$}

Based on comparison of Shannon's true diversity indices associated with each plant, the greatest diversity of predatory arthropods $\left(p_{i}\right)$ was detected on $L$. continentale and $B$. spinosa, followed by $V$. vinifera and Rytidosperma ssp. with a clear gap present between these two pairs of plants (Fig. 2). This suggests incorporating each of these locally-adapted native plants in, and around vineyards, may increase the functional diversity of predatory arthropods more than three times when $B$. spinosa or $L$. continentale is incorporated into a landscape containing vineyards.

\subsubsection{Similarity}

The Jaccard index of similarity for predatory morphospecies (Table 1), was highest between $B$. spinosa and
L. continentale. Conversely, Rytidosperma ssp. consistently exhibited the lowest number of shared morphospecies with other plant pairs. Wallaby grasses provide valuable habitat for morphospecies other than those commonly found in association with the woody perennial plants. If Rytidosperma ssp. are included in a plant assemblage with each woody plant species, this could result in a net increase in predator morphospecies of $25 \%$ to $30 \%$.

\subsection{Insectary plants}

Flowering phenology was assessed for each plant. The flowering period of $V$. vinifera occurred from 30 November to 13 December 2013 and the fruit was picked on 3 April 2014 in the Adelaide Hills. The flowering period of $V$. vinifera in the other two districts occurred from 11 November to 18 November 2013, and the fruit was picked on 14 March in the Barossa Valley and 7 April 2014 in the Eden Valley. Leptospermum continentale flowered from August to December, Rytidosperma ssp. flowered in December and B. spinosa flowered from December to February. The insectary plants flowered at times which overlapped with the flowering and fruit set period of $V$. vinifera, which is a critical time for E. postvittana activity and potential crop damage.

Predatory arthropods showed a clear pattern of seasonal abundance on all plants. Natural enemies were most abundant from October to January on B. spinosa, $L$. continentale and $V$. vinifera and from October to December on Rytidosperma ssp. (Fig. 3).

This period coincides with the peak time that predators are needed for crop protection during flowering and in the lead up to harvest. The presence of predatory arthropods reduced as weather conditions became less favourable (hot and dry) and access to floral resources diminished.

\section{Discussion}

\subsection{Associations between insectary plants and predatory arthropods}

These studies identified associations between three native Australian plants, B. spinosa, L. continentale, Rytidosperma ssp. and predatory arthropods that could support biocontrol of pests in vineyards. Bursaria spinosa and $L$. continentale were associated with a wide range of spiders, lacewings, predatory bugs and beetles. Wolf spiders, earwigs, brown lacewings, and predatory beetles were found abundantly in association with Rytidosperma ssp. 

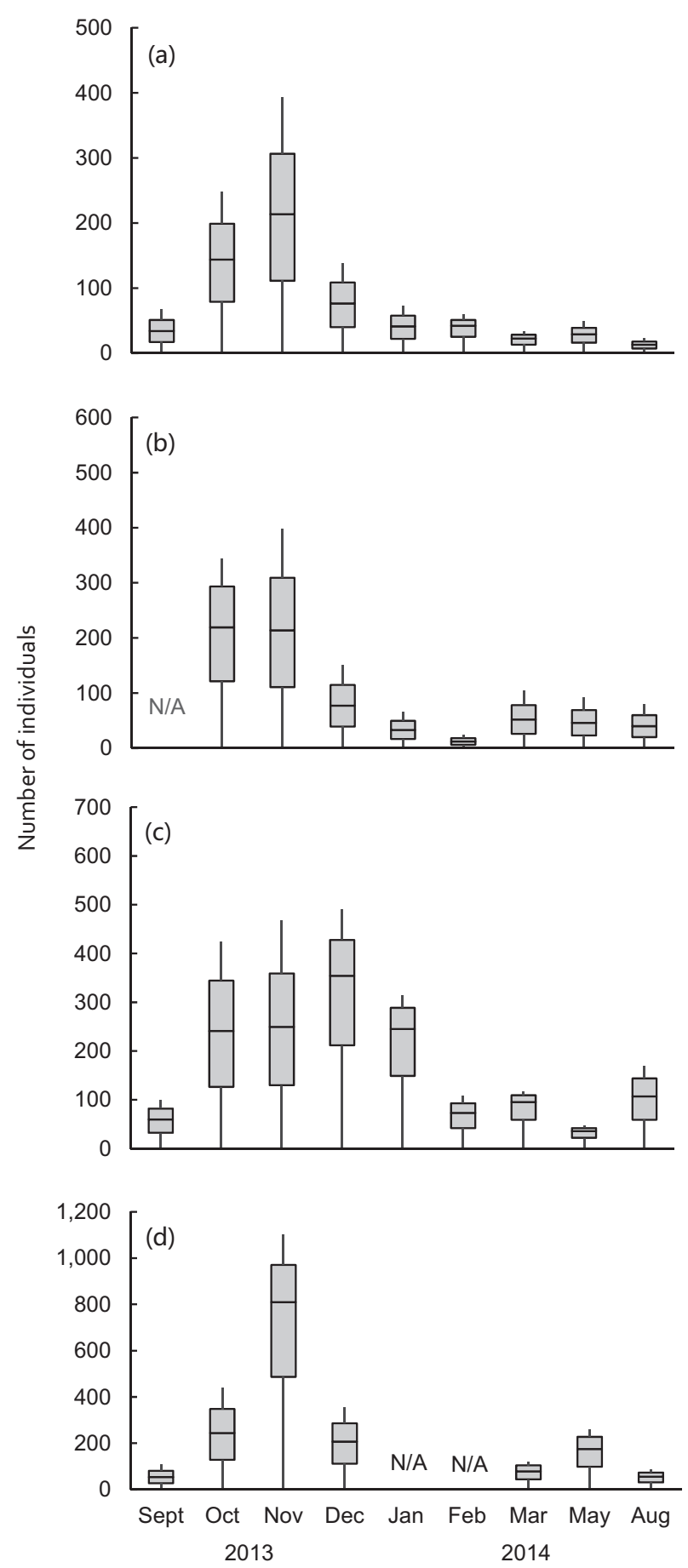

Figure 3. Temporal abundance of predator arthropods pooled across all sites (a) Bursaria spinosa $(n=26)$; (b) Leptospermum continentale $(n=11)$; (c) Vitis vinifera $(n=26)$; and (d) Rytidosperma spp. $(n=16)$ over a 12 -month period. The box plots represent the median (central line), first and third quartiles (grey box), and the whiskers the total range. N/A, no data collected.

\subsection{Seasonal synchrony and overwintering}

Native plants are naturally adapted and can provide insectary benefits throughout the year. The species selected provide floral resources, which when seasonally present, increase the potential of predators to provide control during the critical spring/summer period when pests typically move into the vineyard. Grapevines are deciduous. The reduction in insectary resources during dormancy may result in a resource bottleneck, resulting in an interruption in the presence of predators and parasitoids that may otherwise breed continuously [36]. In contrast, $B$. spinosa and $L$. continentale are both evergreen plants and have the capacity to support populations of mobile predators throughout the year in Australia that can passively populate vineyards and provide continuity of resources. The seasonality of ecosystem services in vineyards could be extended by planting a range of suitable native perennial plants such as. B. spinosa, L. continentale and Rytidosperma ssp., thereby ensuring habitat permanency and synchrony of provisioning services. Furthermore, wallaby grasses appear to have unique attributes that create strong associations with complementary species, such wolf spiders, brown lacewings and glossy shield bugs. This indicates that Rytidosperma ssp. should be an supplementary component to a mix of native, woody plants to enhance insectary benefits.

\subsection{Predatory arthropods}

We found a range of predators that were abundant. High abundance values are often associated with species adapted to site characteristics and are regarded as being present in a 'suitable' habitat [37]. We were able to determine the common predators relevant to Australian vineyards. Predators with a range of functionalities and habitat preferences, which are present at the same time, and/or succeed one another are needed to optimise complementarity benefits, enhancing their capacity to attack different life stages of the pest simultaneously [38-40].

\subsection{Functional diversity}

A functional diversity of predatory arthropods is desirable to target different life stages of economically damaging pests to enhance pest suppression [41]. Top down control of pests can be strengthened when a range of predators complement each other $[42,43]$. The analyses reveals that each of the three insectary plant species has the capacity to contribute to an increase in functional diversity and enhance the diversity and abundance of predatory arthropods when planted in association with a vineyard. A comparison of diversity indices among them shows that the woody native plants are associated with a higher number of arthropod morphospecies overall, as well as a higher number of predatory morphospecies, when compared to grapevines or wallaby grass. Rytidosperma ssp. are associated with dissimilar predatory arthropods, which should provide complementarity functional diversity [44]. Diverse assemblages of predatory arthropods are preferred as they are frequently more effective in reducing the density of herbivore pests [40].

Morphospecies accumulation curves provide a useful measure to predict the richness of arthropods on each plant by using a standard number of sampling units [45]. Each curve approached an upper asymptote, which suggests that the most common species are included in the species inventories and sampling has exceeded the minimum effort required for adequate completeness of the inventories [46]. Bursaria spinosa and L. continentale are associated 
Table 2. Estimated number of shared and unique predator morphospecies associated with each and with one another.

\begin{tabular}{|c|c|c|c|c|c|c|c|c|c|}
\hline \multirow[t]{4}{*}{ Focal plant species } & \multicolumn{9}{|c|}{ Comparative plant species } \\
\hline & \multicolumn{3}{|c|}{ Bursaria spinosa } & \multicolumn{3}{|c|}{ Leptospermum continentale } & \multicolumn{3}{|c|}{ Vitis vinifera } \\
\hline & \multirow[t]{2}{*}{ Shared } & \multicolumn{2}{|c|}{ Unique } & \multirow[t]{2}{*}{ Shared } & \multicolumn{2}{|c|}{ Unique } & \multirow[t]{2}{*}{ Shared } & \multicolumn{2}{|c|}{ Unique } \\
\hline & & Sp. 1 & Sp. $n$ & & Sp. 2 & Sp. $n$ & & Sp. 3 & Sp. $n$ \\
\hline \multicolumn{10}{|l|}{ Predator } \\
\hline \multicolumn{10}{|l|}{ Bursaria spinosa (Sp.1) } \\
\hline Leptospermum continentale (Sp.2) & 52 & 15 & 11 & & & & & & \\
\hline Vitis vinifera $(\mathrm{Sp} .3)$ & 42 & 25 & 14 & 44 & 19 & 12 & & & \\
\hline Rytidosperma ssp. (Sp.4) & 21 & 46 & 17 & 19 & 44 & 19 & 23 & 33 & 15 \\
\hline
\end{tabular}

with a higher richness of arthropod morphospecies. Greater numbers of species are important requirement for ecosystem multifunctionality [47-50]. The similar number of morphospecies found on the woody plants indicates they may provide comparable habitat features. This is likely partly due to the evergreen nature of these shrubs.

Additional measures of diversity also provide a more comprehensive picture of the communities associated with each plant. Shannon's transformed measure $\left(p_{i}\right)$, clearly estimates the true diversity of arthropods associated with each plant when species are considered together in total and in functional groups [30]. A comparison of the indices suggests that $L$. continentale and $B$. spinosa have a greater capacity to enhance functional biodiversity. Both plants have the capacity to enhance the functional diversity of the system by more than three times when they are planted in association with grapevines. Similarly, the inclusion of all three insectary plants in and around vineyards could nearly double the predatory morphospecies richness. If such an increase can be realised, then the overall effectiveness of biological pest control could be enhanced by adding functional redundancy [51].

A resource bottleneck may result in an interruption in the presence of predators and parasitoids that may otherwise breed continuously in the presence of nourishing sources of food and prey [36]. Due to the seasonality of foliage growth of grapevines and wallaby grass, the reduction in resources during dormancy, particularly shelter and the availability of alternative prey, may result in a decline in provisioning resources available to predators. Moreover, it should be possible to fill resource gaps during the growing season of grapevines. The flowering period of $L$. continentale is typically from August to December while B. spinosa flowers from November to February [26]. Therefore, it is possible to have plants that flower over seven months of the growing season or more, if the appropriate species are planted in combination with vineyards. This would extend the period when floral resources are available to natural enemies. These plants could also serve as a refuge. Spray application against fungal pathogens and insects, as well as some soil management practices, can adversely affect arthropod populations [52]. The presence of insectary plants planted nearby should facilitate recolonisation of vineyards by predator populations after disturbances [53].

The dissimilarities of morphospecies diversities between grapevines and each prospective insectary plant suggest that they are associated with arthropods that may have different traits that provide complementary functions compared to those that are more common on grapevines
[54]. For example, perennial cover crops can function as an 'ecological turn-table', which has the capacity to activate and influence key processes and components of an agroecosystem [24]. Wallaby grasses provide habitat for predatory morphospecies that are not commonly found in association with woody plants. European earwigs, wolf spiders and brown lacewings were species that were more commonly found in association with wallaby grasses. Each of these predators are likely to contribute to biological pest control, as they are reported to feed on larvae of E. postvittana and other Lepidoptera that cause damage in vineyards $[5,7,15,55-58]$. The lower degree of predatory species overlap with the other plant species implies that Rytidosperma ssp. should add different and potentially complementary diversity to a vineyard ecosystem. This is consistent with the hypothesis that more species are needed to assure function [44]. The growth habit of Rytidosperma ssp. makes these grasses conducive to being planted undervine and in the mid-row areas where woody plants are unsuitable.

A greater complexity of habitat structure can contribute to greater arthropod diversity, as has been demonstrated in previous studies on spider communities [56,59-61]. Species rich plantings are preferred to support multiple trophic levels of arthropods [62]. Plant diversification promotes diverse arthropod communities that may provide greater stability of ecosystem provisioning [63]. Larger natural areas of vegetation are favoured but the vegetation that remains is often fragmented in production systems. The conservation of small patches may present a good strategy to maximise diversity within the landscape, especially for plants and arthropods that require smaller habitats in association with simple production landscapes [64].

Research indicates that growers are willing to adopt appropriate advice about the use of non-crop insectary plants based on sound research [21]. The three plant species considered here are examples of plants that could contribute to such a strategy for vineyards. The different arthropod communities found in association with perennial grass strips, native evergreen plants and deciduous vines could combine in a landscape that provides more consistent biological control of damaging arthropods.

\section{Conclusion}

This study identified associations between native insectary plants B. spinosa, L. continentale and Rytidosperma ssp., and predatory arthropods in and around vineyards, Each 
plant species supports diverse predatory species, which should attack a range of other arthropods across their life stages. The native plants are naturally adapted and can provide insectary benefits throughout the year, especially during spring and summer to boost the activity of predators and reduce pest pressure on developing fruit.

Our findings indicate that the native, perennial, evergreen plants $B$. spinosa and $L$. continentale have the capacity to support a higher diversity of predators than grapevines alone, and hence could increase the abundance and diversity of predators in the associated grapevines. By incorporating each of these native plant assemblage in and around vineyards it may be possible to increase the functional diversity offered by predatory arthropods, by more than three times when B. spinosa and L. continentale are incorporated versus grapevines only. Rytidosperma ssp. should provide complementarity through its association with dissimilar predatory arthropods. When Rytidosperma ssp. is included in a plant assemblage with of each woody plant species and grapevine, this could result in a further net increase in predator morphospecies richness in the order of $27 \%$.

The incorporation of native insectary plants B. spinosa, L. continentale and Rytidosperma ssp. has the potential to enhance biodiversity in a vineyard. This could improve biological control by providing a suitable habitat to support diverse and functional populations of predatory arthropods. Vineyard managers are encouraged to explore the use of insectary plants in association with vineyards.

This research was made possible through scholarships to Mary Retallack awarded by the Australian Government Research Training Program Stipend, The University of Adelaide C. J. Everard Supplementary Scholarship, SARDI Women's Suffrage Centenary Bursary, and the Grape and Wine Research and Development Corporation (GWRDC) PhD Supplementary Scholarship (GWR Ph1209). Project operating support was provided by GWRDC and Adelaide Hills Wine Region Post Graduate Biodiversity Study Grant. We thank managers who allowed us to collect data in their vineyards: Mrs Prue Henschke, C. A. Henschke and Co, Mr Craig Markby, C. A. Henschke and Co., and Mr Dan Falkenberg, Eden Hall Wines.

\section{References}

[1] P.B. Scholefield, J. Morison, Assessment of Economic Cost of Endemic Pest and Diseases on the Australian Grape and Wine industry. GWR 08/04 (Grape and Wine Research and Development Corporation: Adelaide, 2010)

[2] K.L. Ferguson, Association of Botrytis Bunch Rot with Light Brown Apple Moth (The University of Adelaide, Adelaide, 1995)

[3] L.J. Thomson, D.J. Sharley, A.A. Hoffmann, Aust. J. Exp. Agric. 47, 404 (2007)

[4] R. Isaacs, et al., Front. Ecol. Environ. 7, 196 (2009)

[5] C. Paull, The Ecology of Key Arthropods for the Management of Epiphyas Postvittana (Walker) (Lepidoptera: Torticidae) in Coonawarra vineyards, South Australia, in School of Earth and Environmental Sciences (Adelaide University, Adelaide, 2007), p. 133

[6] C.I. Nicholls, M.A. Altieri, L. Ponti, Proceedings of the International Symposium on Grape Production and Processing, edited by P.G. Adsule, I.S. Sawant, and S.D. Shikhamany (2008), p. 263
[7] L.J. Thomson, A.A. Hoffmann, Biol. Control 49, 259 (2009)

[8] L.J. Thomson, et al., Biol. Control 54, 248 (2010)

[9] P. Barbosa, P. Barbosa (Ed.), Conservation Biological Control (San Diego: Academic Press, 1998), p. 39

[10] P. DeBach, Biological Control by Natural Enemies (Cambridge, UK: Cambridge University Press, 1974)

[11] G.S. Begg, et al., Crop Protection 97, 145 (2017)

[12] A.K. Fiedler, D.A. Landis, S.D. Wratten, Biol. Control 45, 254 (2008)

[13] H.F. van Emden, In Proceedings of the 1st International Symposium on Biological Control of Arthropods (Honolulu, Hawaii, 2002)

[14] I.M. Smith, A.A. Hoffmann, L.J. Thomson, Agric. Forest Entomol. 17, 120 (2015)

[15] L.J. Thomson, A.A. Hoffmann, Biol. Control 52, 160 (2010)

[16] V. Gagic, C. Paull, N.A. Schellhorn, Austral Entomol. 57, 194 (2018)

[17] L.J. Thomson, A.A. Hoffmann, Vegetation Increases Abundance of Natural Enemies of Common Pests in Vineyards (The Australian and New Zealand Grapegrower and Winemaker, 2008), p. 34

[18] A.M. Barnes, S.D. Wratten, H.S. Sandhu, In Procedings of the Fourteenth Australian Wine Industry Technical Conference, edited by R.J. Blair, T.H. Lee, I.S. Pretorius (The Australian Wine Industry Technical Conference: Glen Osmond, SA, Australia, 2010), p. 239

[19] G.M. Gurr, et al., Annu. Rev. Entomol. 62, 91 (2017)

[20] A.K. Fiedler, D.A. Landis, Environ. Entomol. 36, 878 (2007)

[21] M.W. Shields, et al., Peerj 4 (2016)

[22] A. Danne, et al., Environ. Entomol. 39, 970 (2010)

[23] S. Pandey, A. Rahman, G.M. Gurr, Entomologia Experimentalis Et Applicata, 166, 265 (2018)

[24] M.A. Altieri, Agric. Ecosyst. Environ. 74, 19 (1999)

[25] S. Winter, et al., J. Appl. Ecol. 55, 2484 (2018)

[26] M.J. Retallack, M.A. Keller, L.J. Thomson, Aust. J. Grape Wine Res. 25, 233 (2019)

[27] M.J. Retallack, The Potential Functional Diversity Offered by Native Insectary Plants to Support Populations of Predatory Arthropods in Australian Vineyards, PhD Thesis, in School of Agriculture, Food and Wine (University of Adelaide: Adelaide, 2019), p. 193

[28] R.H. Whittaker, Taxon 1972, 213

[29] J. Oksanen, et al., Vegan: Community ecology package. $R$ package version 2.5-3 https://CRAN.Rproject.org/package=vegan in $R$ version 3.5.0 (2018-04-23) 'Joy in playing' 2018

[30] L. Jost, Oikos, 113, 363 (2006)

[31] R.H. Macarthur, Biol. Rev. 40, 510 (1965)

[32] M.A. Adelman, Rev. Econ. Stat. 51, 99 (1969)

[33] G.P. Patil, C. Taillie, J. Amer. Stat. Assoc. 77, 548 (1982)

[34] M. Gardener, Statistics for Ecologists using $R$ and Excel, 2nd ed. (Exeter, Pelagic Publishing, 2017)

[35] I.D. Naumann, The insects of Australia: A Textbook for Students and Research Workers, 2nd ed. (Melbourne, Australia: CSIRO Publishing, 1991) 
[36] N.A. Schellhorn, V. Gagic, R. Bommarco, Trends Ecol. Evol. 30, 524 (2015)

[37] J. VanDerWal, et al., Amer. Naturalist, 174, 282 (2009)

[38] R.D. Holt, J.H. Lawton, Annu. Rev. Ecol. Syst. 25, 495 (1994)

[39] J.E. Losey, R.F. Denno, Ecol. Appl. 9, 378 (1999)

[40] B.J. Cardinale, et al., Ecol. Lett. 6, 857 (2003)

[41] B.N. Hogg, K.M. Daane, Ecol. Entomol. 39, 149 (2014)

[42] D.K. Letourneau, et al., Annu. Rev. Ecol. Evol. Syst. 573 (2009)

[43] G.M. Gurr, S.D. Wratten, J.M. Luna, Basic Appl. Ecol. 4, 107 (2003)

[44] D. Montoya, L. Rogers, J. Memmott, Trends Ecol. Evol. 27, 666 (2012)

[45] C.E. Moreno, G. Halffter, J. Appl. Ecol. 38, 487 (2001)

[46] S.J. Willott, J. Appl. Ecol. 38, 484 (2001)

[47] A. Hector, R. Bagchi, Nat. 448, 188 (2007)

[48] J.E.K. Byrnes, et al., Methods Ecol. Evol. 5, 111 (2014)

[49] J.S. Lefcheck, et al., Nat. Commun. 6 (2015)
[50] D.U. Hooper, et al., Ecol. Monogr. 75, 3 (2005)

[51] D.K. Letourneau, et al., Ecol. Econ. 120, 215 (2015)

[52] S. Yachi, M. Loreau, Proc. Nat. Acad. Sci. USA 96, 1463 (1999)

[53] T. Tscharntke, et al., Ecol. Lett. 8, 857 (2005)

[54] M. Loreau, Oikos, 91, 3 (2000)

[55] M. Bernard, et al., Aust. New Zealand Grapegrower Winemaker 512, 37 (2006)

[56] C.F. D'Alberto, A.A. Hoffmann, L.J. Thomson, Biocontrol. 57, 541 (2012)

[57] S.D. Frank, et al., Biolog. Control 41, 230 (2007)

[58] B.N. Hogg, et al., Entomologia Experimentalis Et Applicata 151, 65 (2014)

[59] M.J. Costello, K.M. Daane, Environ. Entomol. 26, 142 (1997)

[60] B.N. Hogg, K.M. Daane, Ecolog. Entomol. 40, 69 (2015)

[61] N. Rosas-Ramos, et al., Agric. Ecosyst. Environ. 265, 244 (2018)

[62] S. Soliveres, et al., Nature 536, 456 (2016)

[63] E.M. Lichtenberg, et al., Glob Chang Biol. (2017)

[64] T. Tscharntke, et al., Ecol. Res. 17, 229 (2002) 